\title{
THE
}

2013

\section{A multitrait-multimethod matrix investigation of hoarding}

Joseph F. Meyer

University of Rhode Island

Randy O. Frost

Timothy A. Brown

Gail Steketee

David F. Tolin

Follow this and additional works at: https://digitalcommons.uri.edu/psy_facpubs

This is a pre-publication author manuscript of the final, published article.

Creative Commons License

(c) (i) (8)

This work is licensed under a Creative Commons Attribution-Noncommercial-No Derivative Works 4.0 License.

\section{Citation/Publisher Attribution}

Meyer, J. F., Frost, R. O., Brown, T. A., Steketee, G., \& Tolin, D. F. (2013). A multitrait-multimethod matrix investigation of hoarding. Journal of Obsessive-Compulsive and Related Disorders, 2(3), 273-280. doi: 10.1016/j.jocrd.2013.03.002

Available at: https://doi.org/10.1016/j.jocrd.2013.03.002 


\title{
A Multitrait-Multimethod Matrix Investigation of Hoarding
}

\author{
Joseph F. Meyer, \\ University of Rhode Island \\ Randy O. Frost, \\ Smith College \\ Timothy A. Brown, \\ Center for Anxiety and Related Disorders, Boston University \\ Gail Steketee, and \\ Boston University School of Social Work \\ David F. Tolin \\ Hartford Hospital, Institute of Living, Phone: 617-721-8232
}

\section{Abstract}

Hoarding is a serious and potentially life-threatening mental health problem that, until recently, was considered a subtype of OCD. However, recent research suggests it is distinct and more prevalent than OCD. Three key defining features have emerged in factor analytic studies of hoarding scales: excessive acquisition, difficulty discarding, and excessive clutter. Covariation among these defining features has received limited attention. The primary aim of the current study was to examine the role of the three key features in defining hoarding disorder. Convergent and discriminant validity of the three hoarding factors were examined in a multitrait-multimethod matrix. A secondary aim was to examine the extent to which each hoarding feature distinguished individuals meeting criteria for hoarding from those with OCD and community controls. Although the three-factor model provided an adequate fit for the data and convergent validities were high, the hoarding factors evidenced poor discriminant validity across measures. The findings provide preliminary support for a more parsimonious merging of the clutter, acquisition, and discarding subscales versus parsing out subscale scores. Specifically, the active acquisition of items, buildup of clutter, and difficulty discarding accumulated possessions co-occurred strongly enough to be considered a unidimensional construct. Thus, these symptoms were less attributable to separate phenomena and better conceived as part of a cohesive hoarding phenotype. Each of the three factors discriminated hoarding participants from OCD patients and community controls, but did not discriminate the latter two groups. The findings have implications for treating acquisition as a specifier in DSM-5.

\section{Keywords}

hoarding; obsessive-compulsive disorder; multitrait-multimethod matrix; psychometrics; DSM-5

\footnotetext{
(C) 2012 Elsevier Inc. All rights reserved.

Corresponding Author: Joseph F. Meyer, Department of Psychology, University of Rhode Island, joe.meyer518@ gmail.com.

Publisher's Disclaimer: This is a PDF file of an unedited manuscript that has been accepted for publication. As a service to our customers we are providing this early version of the manuscript. The manuscript will undergo copyediting, typesetting, and review of the resulting proof before it is published in its final citable form. Please note that during the production process errors may be discovered which could affect the content, and all legal disclaimers that apply to the journal pertain.
} 
Hoarding is a serious and potentially life-threatening mental health problem with many harmful repercussions for sufferers and their families (Tolin et al, 2008a, 2008b). Symptoms of hoarding are highly prevalent, affecting an estimated 2 to $6 \%$ of the population (Iervolino et al, 2009; Mueller et al, 2009; Samuels et al, 2008; Timpano et al, 2011), and appear to be heritable, with $50 \%$ of their variance attributable to genetic factors (Iervolino et al, 2009). Mean age of onset estimates range from 11 to 15 years, and symptoms typically begin to manifest between middle adolescence and adulthood (Grisham, Frost, Steketee, Kim, \& Hood, 2006; Tolin et al., 2010). Compared to non-hoarding patients with obsessivecompulsive disorder (OCD), those with hoarding endorse lower satisfaction in the quality of life domains of personal safety and living conditions in addition to more severe functional impairment (Saxena et al, 2011), the latter holding especially true among those with late-life hoarding (Ayers, Schiehser, Liu, \& Wetherell, in press). Hoarding problems have historically responded poorly to treatment (Steketee \& Frost, 2003), although cognitivebehavior therapy adapted for hoarding has shown promise (Steketee, Frost, Tolin, Rasmussen, \& Brown, 2010).

Until very recently, hoarding was thought of as a subtype of OCD (Mataix-Cols et al., 2010). Hoarding and OCD share some phenomenological similarity in that the characteristic fear of losing important things appears similar to obsessions, the avoidance of discarding may be functionally similar to compulsions, and excessive concern over other people touching or moving one's possessions resembles symmetry obsessions. Moreover, significant correlations have been found between hoarding and other OCD symptoms (see Mataix-Cols et al, 2010), and people with hoarding problems report more OCD symptoms than do those without such symptoms (Frost et al, 1996).

However, hoarding and OCD differ in a number of ways. Unlike OCD, people who hoard experience distress largely because of the consequences of the behavior (e.g., cluttered rooms, conflict with authorities over the clutter) and not the thoughts about possessions. With hoarding, there is no urge to perform rituals to control a thought. Hoarding is often associated with positive emotions (during acquisition and reviewing saved items) and grief at attempts to discard, emotions that are seldom part of OCD (Mataix-Cols et al, 2010). Furthermore, substantial numbers of people with hoarding problems have no other OCD symptoms. Frost et al. (2011) reported that among a large sample of hoarding patients, only $18 \%$ met diagnostic criteria for OCD, with higher rates of comorbidities for depression, generalized anxiety disorder, and social phobia. Tolin and colleagues (2011) reported hoarding symptoms in $29 \%$ of GAD patients, compared to only $17 \%$ of OCD patients. Finally, although hoarding symptoms may correlate with OCD symptoms, the magnitude of these correlations is much smaller than correlations among more classic symptoms of OCD (Abramowitz et al, 2003). Other evidence of its distinctiveness comes from genetic (Samuels et al, 2007a, 2007b), neuroimaging (An et al, 2009; Saxena et al., 2004; Tolin et al, 2009; Tolin et al, 2012), and treatment outcome studies (Abramowitz et al., 2003). These features have led to the recommendation that hoarding be considered a separate disorder in the revision of the Diagnostic and Statistical Manual of Mental Disorders (Mataix-Cols et al, 2010).

As first proposed by Frost and Hartl (1996), clinical hoarding consists of (a) acquisition of and difficulty discarding a large number of personal items, especially those of limited value or utility, due to strong urges to save items and/or avoid distress, (b) cluttered personal living space (e.g., at home or in occupational settings) resulting from the accumulation of possessions, and (c) clinically significant distress, functional impairment, and/or risks to health and safety associated with hoarding. This tripartite definition emerged from a body of research on both clinical and non-clinical cases of hoarding using self-report measures and clinical interviews (e.g., Frost \& Gross, 1993; Frost, Hartl, Christian, \& Williams, 1995; 
Frost, Krause, \& Steketee, 1996). Embedded in these clinical criteria are three key defining features that have emerged in factor analytic studies of hoarding scales, namely, excessive acquisition, difficulty discarding, and excessive clutter (Frost, Steketee, \& Grisham, 2004).

The Frost and Hartl (1996) tripartite hoarding formulation was further elaborated and refined in the recommended criteria for hoarding disorder (HD) drafted for the forthcoming fifth edition of the Diagnostic and Statistical Manual of Mental Disorders (DSM-5). As discussed by Mataix-Cols and colleagues (2010), the proposed DSM-5 criteria treat excessive acquisition as a diagnostic specifier in light of evidence that (a) this symptom has not been detected among all individuals with compulsive hoarding (Frost, Tolin, Steketee, Fitch, \& Selbo-Bruns, 2009), and (b) excessive acquisition may be more strongly related to the content of obsessions in some OCD cases, which may result in some degree of criterion contamination. In contrast, the original tripartite definition included acquisition as a key feature of hoarding, which remains tenable given that a large majority of participants with hoarding appear to meet criteria for excessive acquisition via both self-report and observations submitted by family informants (for details, see Frost et al, 2009).

Further bolstering the reliability and validity of the proposed HD criteria was a recently completed London field trial, which included semi-structured diagnostic assessments of participants suffering from severe HD symptoms (Mataix-Cols, Billotti, Fernández de la Cruz, \& Nordsletten, 2013). Of the 50 participants reporting HD symptoms, 29 met DSM-5 HD criteria, whereas none of the self-identified "collectors" met criteria. Results revealed predominantly high sensitivities (range $=.64$ to 1 ), specificities (range $=.98$ to 1 ), and interrater reliabilities (.68 to .97) for the overall HD diagnosis as well as each individual criterion. In addition, most participants diagnosed with HD perceived the proposed DSM-5 criteria as useful and not overly stigmatizing. Also, consistent with results from the Frost et al. (2009) study, $95-100 \%$ of the HD cases met criteria for the excessive acquisition specifier (Mataix-Cols et al., 2013), which offers further evidence of the general ubiquity of this symptom among individuals with HD.

Despite ongoing advances in hoarding research since the late 1990s, inadequacies in both defining and measuring the construct of hoarding remain unaddressed. Specifically, although most pertinent subscales contained in popular measures of OCD symptoms evidence sound psychometric properties (e.g., the Obsessive-Compulsive Inventory-Revised [OCI-R; Foa et al., 2002]; Schedule of Compulsions, Obsessions, and Pathological Impulses [SCOPI; Watson \& Wu, 2005]; Vancouver Obsessional Compulsive Inventory [VOCI; Thordarson et al, 2004]; and Yale-Brown Obsessive-Compulsive Scale [Y-BOCS; Goodman et al., 1989]), item development for older measures was not informed by recent advances in research. Thus, the lack of inclusion of the three key hoarding dimensions (Frost \& Hristova, 2011) compromises construct validity for these instruments. For example, the categorical YBOCS hoarding items (Goodman et al, 1989) do not tap the key symptom domains originally outlined by Frost and Hartl (1996), and the Hoarding Subscale of the original OCI did not reliably differentiate healthy from pathological acquisition of possessions (Foa et al., 1998). Item content inconsistencies across different measures, both old and new, are likely partly to blame for the wide variability observed in comorbidity patterns (see Frost, Steketee, \& Tolin, 2011), adding further confusion to the literature.

Covariation among the three defining facets of hoarding (viz., excessive acquisition, clutter, and difficulty discarding) has also received limited attention in recent years. Using a large sample of hoarding participants, Frost et al. (2004) conducted a psychometric investigation of the Saving Inventory-Revised (SI-R), which revealed moderate degrees of interrelatedness among the hoarding factors. Specifically, acquisition was modestly correlated with clutter $(r=.31)$ and difficulty discarding $(r=.45)$, whereas clutter was more 
strongly associated with discarding problems $(r=.56)$. Moreover, the five items comprising the Hoarding Rating Scale-Interview (HRS-I; Tolin, Frost, \& Steketee, 2010), which cover the same core features of hoarding in addition to emotional distress and functional impairment, were strongly correlated with one another ( $r \mathrm{~s}=.77$ to .91$)$. Further research is needed to clarify the magnitude and stability of associations among these domains, preferably beyond exclusively self-report measures (e.g., additional semi-structured interviews).

The primary aim of the current study was to examine the role of the three key features of hoarding in psychometrically delineating the disorder through the use of multiple ratings of degrees of clutter, acquisition, and discarding across three different measures. As such, this study represents one of the first hoarding studies using multi-method assessment. The use of multiple hoarding assessment techniques addresses suggestions and limitations noted in previous studies (e.g., Grisham et al, 2006; Wu \& Watson, 2005), namely, the supplementation of self-report ratings with data gleaned from observational assessments (e.g., semi-structured clinical interview data provided by HRS-I). Through an assessment of the convergent and discriminant validity of the three hoarding factors in a multitraitmultimethod matrix (see hypothesized measurement model illustrated in Figure 1), the nature of hoarding symptoms may be more clearly illuminated via triangulation, which aids in circumventing inaccuracies known to arise from self-evaluations of hoarding symptoms (e.g., Frost \& Gross, 1993).

A secondary aim was to reveal the extent to which each hoarding feature distinguished individuals meeting criteria for hoarding from those with OCD and community controls (see Figure 2 for hypothesized measurement model). Given the aforementioned research findings pointing to a clear differentiation of hoarding from OCD, it was hypothesized that the hoarding group would score higher on measures of clutter, acquisition, and discarding compared to OCD patients and community controls.

\section{Method}

\section{Participants}

Hoarding participants were recruited from health and mental health clinics, newspapers, informational websites, and through investigator media appearances. OCD participants were recruited from anxiety and mental health clinics, as well as media and advertisements. Community controls were recruited through newspaper and internet advertisements for people without a psychiatric history and were not permitted to meet criteria for any mental health disorder, except for a diagnosis of specific phobia. Recruitment and all assessments took place at Boston University and Hartford Hospital.

All participants were 18 years of age or older. Inclusion in the Hoarding (HD) group required interviewer ratings of moderate or greater clutter, difficulty discarding, and either distress or impairment from hoarding on the HRS-I. In addition, the clutter and difficulty discarding could not be attributed to another OCD symptom (e.g., contamination, checking). Of note, hoarding was not required to be the principal (i.e., most severe) clinical difficulty for the HD group. OCD participants, on the other hand, had a principal DSM-IV diagnosis of OCD (non-hoarding) as determined by trained diagnostic interviewers using the Anxiety Disorders Interview Schedule for DSM-IV: Lifetime Version (ADIS-IV-L; Di Nardo, Brown, \& Barlow, 1994). Concurrent hoarding symptoms were required to be below moderate levels (i.e., not qualify for HD group) based on the HRS-I.

Study candidates were excluded if they (a) reported suicidal ideation or other risk factors requiring immediate attention, (b) had current psychotic symptoms, (c) reported substance 
abuse or dependence within the past 3 months, or (d) showed significant cognitive impairment such as mental retardation or dementia (assessed using the Orientation-MemoryConcentration Test; Katzman et al, 1983) that could compromise their ability to provide informed consent or complete the assessments. Forty-four people (30 HD and 14 OCD) were excluded from the study because their symptoms were sub-clinical, 26 for whom OCD was not their principal diagnosis, and 12 with comorbid exclusionary diagnoses (e.g., psychosis, substance abuse, etc.). The initial sample of participants included 217 with hoarding, 96 with OCD, and 130 community controls.

\section{Measures}

\section{Anxiety Disorders Interview Schedule for DSM-IV: Lifetime Version (ADIS-IV-} L)-The ADIS-IV-L (Di Nardo, Brown, \& Barlow, 1994) is a semi-structured diagnostic interview that assesses the presence and severity of $D S M-I V$ anxiety, mood, substance use, and somatoform disorders. It also screens for the presence of other major Axis I symptoms (e.g., hallucinations and delusions). Inter-rater reliability of ADIS-IV-L ratings is good-toexcellent across current anxiety disorders (range of $\kappa s=.67$ to .86 ; Brown, Di Nardo, Lehman, \& Campbell, 2001).

Hoarding Rating Scale-Interview (HRS-I)—The HRS-I is a semi-structured interview consisting of five questions designed to measure the central features of hoarding (Tolin et al, 2010). Each question is scored on a scale ranging from 0 ("not at all") to 8 ("extreme") to indicate the presence and severity of symptoms. Three of the five questions pertain to the critical components of hoarding (i.e., clutter, difficulty discarding, and excessive acquisition), whereas the remaining two questions gauge degrees of distress and interference associated with reported hoarding. Through the use of optimal cutting scores determined by signal detection analysis (i.e., receiver operating characteristic curves), the HRS-I effectively distinguishes hoarding patients from community controls and OCD patients without significant hoarding symptoms (Tolin et al, 2010). HRS-I scores also evidence high test-retest reliability (albeit with some variance over settings and time) and strong internal consistency, although inter-rater reliability data are currently lacking (see Tolin et al., 2010). In addition, strong associations have been observed between HRS-I and .SI-R total scores, as well as among SI-R items corresponding to specific hoarding features and HRS-I items tapping the same content (e.g., for acquisition, clutter, and discarding), although weaker total-score correlations are evident with general OCD, anxiety, and depression symptoms (Tolin et al, 2010). Of note, HRS-I ratings are sensitive to changes observed during the course of cognitive-behavioral treatment targeting symptoms of hoarding (Steketee et al, 2010).

Obsessive-Compulsive Inventory-Revised (OCI-R)-The OCI-R (Foa et al, 2002) is an 18-item self-report measure of OCD symptom severity. The OCI-R comprises six subscales: obsessing, checking, neutralizing, ordering, washing, and hoarding. Only the 3 items in the hoarding subscale were used in the present investigation ("I collect things I don't need", "I have saved up so many things that they get in the way", and "I avoid throwing things away because I am afraid I might need them later.").

Saving Inventory-Revised (SI-R)-The SI-R (Frost et al, 2004) is a 23-item self-report questionnaire designed to measure symptoms of hoarding. It consists of three subscales (viz., Clutter, Difficulty Discarding, and Excessive Acquisition), and items are scored on a scale of 0 to 4 with total scores ranging from 0 to 92 . Optimal cutoff scores have been established using signal detection analysis for distinguishing clinically significant from subclinical levels of hoarding (see Tolin et al, 2010). SI-R subscales and total scores successfully differentiate hoarding patients from non-hoarding community controls (Frost et 
al., 2004), evidence both strong convergent (Frost et al., 2004; Frost, Steketee, Tolin, \& Renaud, 2008; Tolin et al, 2010) and discriminant (Frost et al., 2004) validity, and reflect reductions in symptom severity attributable to the effects of cognitive-behavioral treatment (Steketee et al, 2010).

\section{Procedure}

The present study was approved by the Institutional Review Boards at Smith College, Boston University, and Hartford Hospital. All participants signed an informed consent form prior to the start of the study at data collection sites at Boston University or The Institute of Living/Hartford Hospital. Clinical interviews were conducted by Master's-level clinical psychologists or postdoctoral fellows trained to criteria using the ADIS-IV-L and supervised by licensed psychologists. The assessment battery consisted of 4-8 hours of assessment that included interviews and questionnaires not used in the current study, including measures of non-hoarding related constructs. While some participants were able to complete the assessment in one session, most participants required two or sometimes three sessions.

\section{Data Analysis}

A latent variable software program with maximum likelihood estimation capabilities (Mplus 5.0, Muthén \& Muthén, 1998-2009) was used to analyze the raw data. To evaluate overall goodness of fit for the correlated uniqueness confirmatory factor analysis (CFA) and subsequent regression analyses, the following indices were utilized: (a) the root mean square error of approximation (RMSEA; Steiger, 1990) with a 90\% confidence interval (90\% CI; MacCallum, Browne, \& Sugawara, 1996), which adjusts for model parsimony, (b) the comparative fit index (CFI; Bentler, 1990) and Tucker-Lewis index (TLI; Tucker \& Lewis, 1973), both of which determine fit relative to a null, independence model, and (c) the standardized root mean square residual (SRMR) statistic, which gauges absolute fit (Jöreskog \& Sörbom, 1986). Regarding acceptability of model fit, the following guidelines were followed: (a) RMSEA values close to or below .08 with upper $90 \%$ CI close to or below .08, (b) CFI and TLI values close to or above .95, and (c) SRMR values close to or below .08 (Hu \& Bentler, 1999). Multiple fit indices were used because these comprise a conservative and reliable evaluation strategy that provides different information regarding degrees of fit (Brown, 2006; Jöreskog, 1993).

The measurement models constructed in this study include latent factors defined by multiple indicators. For example, the multitrait-multimethod (MTMM; cf. Marsh \& Grayson, 1995) measurement model used to evaluate convergent and discriminant validity of hoarding features includes three different measures (viz., the OCI-R, SI-R, and HRS-I) assessing the same symptoms (viz., acquisition, clutter, and discarding). This approach permits the estimation of measurement error, the incorporation of an error theory into the model, the estimation of construct validity, and the enhancement of statistical power (Marsh \& Hau, 1999). With regard to testing the MTMM model, a correlated uniqueness approach (i.e., estimation of method effects via specification of error covariances based on the same assessment methods) will be employed in lieu of a correlated methods approach (i.e., estimation of method effects via specification of method factors). Advantages of the former modeling technique include rare incidence of improper solutions and suspension of the assumption of unidimensional method effects (cf. Brown, 2003; Marsh \& Grayson, 1995).

\section{Results \\ Descriptive Statistics}

Descriptive statistics for participants are presented in Table 1. All three groups had similar age ranges, but the OCD group had a significantly lower mean age, $F(2,399)=87.90, p<$. 
001, than the hoarding and community control groups. Gender distribution also varied significantly across groups, $\chi^{2}(2)=31.6, p<.001$; hoarding and community control participants included more women, whereas men and women were almost equally represented in the OCD sample. With regard to ethnicity, all three groups had similar small numbers of non-Caucasian and Hispanic participants.

\section{MTMM Matrix}

A three-trait (T) by three-method (M) multitrait-multimethod (MTMM) matrix was used to evaluate the construct validity of the tripartite structure of hoarding (i.e., clutter, acquisition, and discarding) as measured by three different assessment methods (i.e., SI-R, OCI-R, and HRS-I) for the sample. This approach also permits the estimation of method effects, or the degree to which construct multidimensionality is attributable to indicator artifacts (e.g., similarly worded items) versus genuine trait covariance. In the $3(\mathrm{~T}) \times 3(\mathrm{M})$ correlation matrix depicted in Table 2, monomethod blocks contain correlations among indicators assessed by the same method, whereas heteromethod blocks consist of indicator correlations measured by different methods.

\section{Correlated Uniquenesses CFA}

A correlated uniqueness CFA model (cf. Marsh \& Grayson, 1995) was conducted using robust maximum likelihood estimation (i.e., MLR; maximum likelihood with robust standard errors and chi-square) to analyze the MTMM data more formally (see Figure 1). The nine indicators correspond to each hoarding dimension (i.e., clutter, acquisition, and discarding) as measured by each assessment method, and each indicator was specified to load on its corresponding trait factor with all cross-loadings fixed to zero. Correlated uniquenesses (i.e., error covariances) were specified among indicators sharing the same assessment method to estimate method effects. Correlations among hoarding factors were freely estimated.

The correlated uniqueness CFA model provided a good fit to the MTMM data, $\chi^{2}(15)=$ $58.03, p<.001 ; \mathrm{RMSEA}=0.08,90 \% \mathrm{CI}=0.062-0.11 ; \mathrm{SRMR}=.02 ; \mathrm{CFI}=.98 ; \mathrm{TLI}=$ 0.96. An examination of fit diagnostics (i.e., standardized residuals and modification indices) did not reveal salient areas of strain in the solution. All completely standardized parameter estimates were statistically significant $(p<.01)$ with the exception of three correlated uniquenesses for the SI-R indicators.

Adjusting for measurement error and method effects, results indicated strong convergent validities for the SI-R, OCI-R, and HRS-I measures of the three hoarding dimensions as evidenced by large and statistically significant $(p<.001)$ trait factor loadings (range $=.84$ to .98). However, poor discriminant validity was apparent among the hoarding dimensions as evidenced by strong and significant $(p<.001)$ trait factor correlations (range $=.92$ to .95 ). Of note, the magnitude of the trait factor correlations closely approximated or exceeded most of the trait factor loadings. For example, the lowest trait factor correlation $(r=.92)$ alone exceeded four of the nine trait factor loadings (range $=.84$ to .90 ). Correlated uniquenesses among indicators assessed by the same method ranged from low to moderately high $(I \mathrm{~s}=.02$ to .50$)$. Method effects were strongest for the HRS-I measures of the hoarding dimensions ( $I \mathrm{~s}=.38$ to .50$)$ and weakest for the SI-R measures of the three constructs $(I \mathrm{~s}=$. 02 to -.32 ). Collective results suggest mixed evidence for the construct validity of hoarding as revealed by strong convergent validity, poor discriminant validity, and mild-to-moderate method effects. 


\section{Regression Analyses}

In the final set of analyses, the hoarding factors from the MTMM measurement model were regressed onto dummy codes $(k-1)$ representing the hoarding, $\mathrm{OCD}$, and community control groups using robust maximum likelihood estimation (see Figure 2). Two separate analyses were conducted, the first with the community control group serving as the reference group, and the second with the hoarding group as the reference group. In both analyses, the correlations between the covariates were freely estimated (i.e., the hoarding group with the OCD group in the first analysis and the control group with the OCD group in the second analysis).

The correlated uniqueness CFA model provided an acceptable fit to the MTMM data, $\chi^{2}$ $(27)=165.31, p<.001 ; \mathrm{RMSEA}=0.11,90 \% \mathrm{CI}=0.10-0.13 ; \mathrm{SRMR}=.02 ; \mathrm{CFI}=.96$; $\mathrm{TLI}=0.92$. Inclusion of the covariates (i.e., group dummy codes) did not perturb the factor structure, and no salient areas of strain in the solution were present. Of note, the observed RMSEA value fell slightly beyond the range of mediocre fit as specified by MacCallum et al. (1996), and the TLI value fell within the marginal (albeit acceptable) range (see Bentler, 1990). However, in light of the absence of substantively important areas of strain, the RMSEA and TLI values are likely explained by the inevitable presence of additional parameter estimates in the correlated uniquenesses CFA-MTMM model (i.e., high parameterization) in tandem with the presence of several non-significant parameter estimates that needed to remain in the model for substantive purposes (e.g., the trait factors regressed onto group dummy codes). To clarify the effect of high parameterization for unfamiliar readers, the inclusion of more variables in a CFA-MTMM model increases the number of factor-variable associations. The increased number of constraints placed on these factor-variable relationships (e.g., more are set to zero) renders models of this nature more falsifiable.

Using control participants as the reference group, the hoarding group evidenced significantly higher scores on clutter $(\gamma=22.32, p<.001)$, acquisition $(\gamma=11.72, p<.001)$, and discarding $(\gamma=14.60, p<.001)$ than the control group. Using the hoarding participants as the reference group, the OCD group obtained significantly lower scores on clutter $(\gamma=$ $-22.61, p<.001)$, acquisition $(\gamma=-11.52, p<.001)$, and discarding $(\gamma=-13.42, p<.001)$ relative to the hoarding group. Each latent variable was in the metric of the corresponding SI-R subscale. For the measurement portion of the model, completely standardized correlated factor residuals ranged from .75 to .83 ( $p s<.001$ ), factor loadings ranged from . 85 to .97 ( $p s<.001$ ), and correlated indicator residuals ranged from .19 to .47 (range of ps $<.001$ to .10). Effect sizes separating the hoarding group from the control group were large (Cohen's $d s=1.62$ to 1.81) as were effect sizes separating the hoarding and OCD groups (Cohen's $d s=-1.60$ to -1.83 ). In contrast, the OCD group did not significantly differ from the control group on any outcome, and the magnitude of these differences was negligible (Cohen's $d s=-0.02$ to 0.14 ).

\section{Discussion}

The current study sought to investigate the construct validity of hoarding using interview and self-report instruments in a multitrait-multimethod matrix. Although the model provided an adequate fit for the data and convergent validities were high (i.e., the three different measures of hoarding features were strongly interrelated while adjusting for method effects), the hoarding factors evidenced poor discriminant validity. These findings preliminarily call into question the psychometric distinctiveness of the three hoarding dimensions and provide tentative support for a more parsimonious merging of the clutter, acquisition, and discarding subscales (versus parsing out subscale scores) in the context of clinical outcome prediction. Thus, the active acquisition of items, buildup of clutter, and difficulty discarding 
accumulated possessions may co-occur strongly enough to be considered a unidimensional construct.

As posited in earlier studies (e.g., Frost et al., 2011), these symptoms appear to be less attributable to separate (i.e., comorbid) conditions and better conceived as part of a cohesive hoarding phenotype. The process (i.e., underlying causes) leading people with hoarding problems to retain possession of objects may be the same one leading to their excessive acquiring. This has implications for the DSM-5 designation of excessive acquisition as a specifier instead of a diagnostic criterion for HD. Existing research suggests that in a small number of hoarding cases, patients deny excessive acquiring (Frost et al, 2009; 2011). However, discrepancies between individual and observer accounts of acquiring problems suggest that recognition and reporting of excessive acquiring may be impaired in people with hoarding problems (Black, 2011; Frost et al, 2009). Recent evidence suggests that even hoarding participants who deny acquiring problems avoid situations containing acquiring cues (Frost, Rosenfield, Steketee, \& Tolin, 2012). A closer examination of acquiring behaviors in HD is warranted to further clarify the nature of the hoarding phenotype.

At this point, it is important to recognize that although a more omnibus theoretical conceptualization of hoarding may turn out to be more informative and psychometrically expedient in research applications (e.g., in the context of etiological and predictive considerations), clinically useful information may still be gleaned from more domainspecific assessments of hoarding symptoms in treatment settings. For example, questions pertaining to different behavioral aspects of hoarding (e.g., excessive acquisition and difficulty discarding) as well as problematic consequences (e.g., a cluttered home environment) remain descriptively relevant for case conceptualization and treatment planning purposes. In this sense, our findings should not be misconstrued as suggesting that information contained within the tripartite definition of hoarding is clinically or conceptually redundant, although partitioning the data in this fashion may remain statistically redundant in future studies. On the other hand, a unitary factor score may prove useful in actuarial prediction scenarios in applied practice (e.g., when attempting to ascertain the likelihood of discrete clinical outcomes; see Dawes, Faust, \& Meehl, 1989).

This study also attempted to ascertain the degree to which hoarding features distinguished hoarding participants from those with OCD. Hoarding participants were found to differ from OCD patients and community controls on all three hoarding factors. This finding is consistent with evidence of weak associations among hoarding and common OCD symptoms (Abramowitz et al, 2008; Wu \& Watson, 2005) as well as factor analytic research revealing the independence of hoarding from OCD symptoms (Bloch, Landeros-

Weisenberger, Rosario, Pittenger, \& Leckman, 2008). These results add to converging lines of evidence suggesting that hoarding may best be considered an independent disorder with its own unique set of primary symptoms, comorbidity profile, neuropsychological weaknesses, and treatment implications. OCD patients and community controls did not differ on any of the three hoarding factors. This finding is not surprising because the participants with both clinically significant hoarding and OCD were assigned to the hoarding group. Without participants with significant hoarding symptoms, the OCD group does not differ from community controls on levels of hoarding behavior.

Several limitations were apparent in the current study. The high frequency of female participants $(76 \%)$ in the hoarding sample, although typical of clinical studies, does not match epidemiological findings regarding gender distribution (Iervolino et al, 2009; Mueller et al, 2009; Samuels et al, 2008; Timpano et al, 2011). These findings may need replication with a sample of males with hoarding problems. The older age of the hoarding sample compared to OCD participants, although also typical of clinical studies of these populations, 
could have influenced differences between groups on symptom severity. The current study relied on two self-report assessments and one interview. MTMM should be extended to domains of assessment that do not rely so heavily on self-report (e.g., behavioral observation, significant other report).

A more complete and accurate understanding of hoarding will hopefully enhance the efficacy of cognitive-behavioral treatments. This is especially important given the less-thanoptimal treatment response of individuals struggling with hoarding (Pertusa et al, 2010; Steketee \& Frost, 2003) and complex comorbidity patterns associated with the disorder (Frost et al, 2011). Efficacious treatment developments inevitably hinge on the thoroughness and accuracy of a clinical understanding of hoarding.

\section{Acknowledgments}

This research was funded by grants from NIMH to Randy Frost (R01 MH068008) and Gail Steketee (R01 MH068007).

\section{References}

Abramowitz JS, Wheaton MG, Storch EA. The status of hoarding as a symptom of obsessivecompulsive disorder. Behaviour Research and Therapy. 2008; 46:1026-1033. [PubMed: 18684434]

American Psychiatric Association. Diagnostic and statistical manual of mental disorders. 4. Washington, DC: Author; 2000.

An SK, Mataix-Cols D, Lawrence NS, Wooderson S, Giampietro V, Speckens A, Phillips ML. To discard or not to discard: The neural basis of hoarding symptoms in obsessive-compulsive disorder. Molecular Psychiatry. 2009; 14:318-331. [PubMed: 18180763]

Ayers CR, Schiehser D, Liu L, Wetherell JL. Functional impairment in geriatric hoarding participants. Journal of Obsessive-Compulsive and Related Disorders. (in press).

Bentler PM. Comparative fit indices in structural models. Psychological Bulletin. 1990; 107:238-246. [PubMed: 2320703]

Black, DW. Assessment of compulsive buying. In: Müller, A.; Mitchell, JE., editors. Compulsive buying: Clinical foundations and treatment. New York: Routledge; 2011. p. 27-50.

Bloch M, Landeros-Weisenberger A, Rosario M, Pittenger C, Leckman J. Meta-analysis of the symptom structure of obsessive-compulsive disorder. American Journal of Psychiatry. 2008; 165:1532-1542. [PubMed: 18923068]

Blom RM, Samuels JF, Grados MA, Chen Y, Bienvenu OJ, Riddle MA, Nestadt G. Cognitive functioning in compulsive hoarding. Journal of Anxiety Disorders. 2011; 25:1139-1144. [PubMed: 21906910]

Brown, TA. Confirmatory factor analysis for applied research. New York: Guilford Press; 2006.

Brown TA. Confirmatory factor analysis of the Penn State Worry Questionnaire: Multiple factors or method effects? Behaviour Research and Therapy. 2003; 41:1411-1426. [PubMed: 14583411]

Brown TA, Di Nardo PA, Lehman CL, Campbell LA. Reliability of DSM-IV anxiety and mood disorders: Implications for the classification of emotional disorders. Journal of Abnormal Psychology. 2001; 110:49-58. [PubMed: 11261399]

Dawes RM, Faust D, Meehl PE. Clinical versus actuarial judgment. Science. 1989; 243:1668-1674. [PubMed: 2648573]

Di Nardo, PA.; Brown, TA.; Barlow, DH. Anxiety Disorders Interview Schedule for DSM-IV: Lifetime version (ADIS-IV-L). New York: Oxford University Press; 1994.

Foa EB, Huppert JD, Leiberg S, Langner R, Kichic R, Hajcak G, Salkovskis PM. The ObsessiveComplusive Inventory: Development and validation of a short version. Psychological Assessment. 2002; 14:485-495. [PubMed: 12501574]

Foa EB, Kozak MJ, Salkovskis PM, Coles ME, Amir N. The validation of a new obsessive-compulsive disorder scale: The Obsessive-Compulsive Inventory. Psychological Assessment. 1998; 10:206214. 
Frost RO, Gross RC. The hoarding of possessions. Behaviour Research and Therapy. 1993; 31:367381. [PubMed: 8512538]

Frost RO, Hartl TL, Christian R, Williams N. The value of possessions in compulsive hoarding. Behaviour Research and Therapy. 1995; 33:897-902. [PubMed: 7487849]

Frost RO, Krause M, Steketee G. Hoarding and obsessive compulsive symptoms. Behavior Modification. 1996; 20:116-132. [PubMed: 8561769]

Frost R, Steketee G, Grisham J. Measurement of compulsive hoarding: Saving Inventory-Revised. Behaviour Research and Therapy. 2004; 42:1163-1182. [PubMed: 15350856]

Frost RO, Steketee G, Tolin DF. Comorbidity in hoarding disorder. Depression and Anxiety. 2011; 28:876-884. [PubMed: 21770000]

Frost R, Steketee G, Tolin D, Renaud S. Development and validation of the Clutter Image Rating. Journal of Psychopathology and Behavioral Assessment. 2008; 30:193-203.

Frost RO, Tolin DF, Steketee G, Fitch KE, Selbo-Bruns A. Excessive acquisition in hoarding. Journal of Anxiety Disorders. 2009; 23:632-639. [PubMed: 19261435]

Goodman WK, Price LH, Rasmussen SA, Mazure C, Fleischmann RL, Hill CL, Charney DS. The Yale-Brown Obsessive Compulsive Scale. I. Development, use, and reliability. Archives of General Psychiatry. 1989; 46:1006-1011. [PubMed: 2684084]

Grisham JR, Brown TA, Savage CR, Steketee G, Barlow DH. Neuropsychological impairment associated with compulsive hoarding. Behaviour Research and Therapy. 2007; 45:1471-1483. [PubMed: 17341416]

Grisham JR, Frost RO, Steketee G, Kim HJ, Hood S. Age of onset of compulsive hoarding. Journal of Anxiety Disorders. 2006; 20:675-686. [PubMed: 16112837]

Hartl TL, Duffany SR, Allen GJ, Steketee G, Frost RO. Relationships among compulsive hoarding, trauma, and attention-deficit/hyperactivity disorder. Behaviour Research and Therapy. 2005; 43:269-276. [PubMed: 15629755]

$\mathrm{Hu}$ L, Bentler PM. Cutoff criteria for fit indices in covariance structure analysis: Conventional criteria versus new alternatives. Structural Equation Modeling. 1999; 6:1-55.

Iervolino AC, Perroud N, Fullana MA, Guipponi M, Cherkas L, Collier DA, Mataix-Cols D. Prevalence and heritability of compulsive hoarding: A twin study. American Journal of Psychiatry. 2009; 166:1156-1161. [PubMed: 19687130]

Jöreskog, KG. Testing structural equation models. In: Bollen, KA.; Long, JS., editors. Testing structural equation models. Thousand Oaks, CA: Sage; 1993. p. 294-316.

Jöreskog, K.; Sörbom, D. LISREL VI: Analysis of linear structural relationships by maximum likelihood and least square methods. Mooresville, IN: Scientific Software; 1986.

Katzman R, Brown T, Fuld P, Peck A, Schechter R, Schimmel H. Validation of a short OrientationMemory-Concentration Test of cognitive impairment. American Journal of Psychiatry. 1983; 140:734-739. [PubMed: 6846631]

MacCallum RC, Browne MW, Sugawara HM. Power analysis and determination of sample size for covariance structure modeling. Psychological Methods. 1996; 1:130-149.

Marsh, HW.; Grayson, D. Latent variable models of multitrait-multimethod data. In: Hoyle, RH., editor. Structural equation modeling: Concepts, issues, and applications. Thousand Oaks, CA: Sage; 1995. p. 177-198.

Marsh, HW.; Hau, KT. Confirmatory factor analysis: Strategies for small sample sizes. In: Hoyle, RH., editor. Statistical strategies for small sample research. Thousand Oaks, CA: Sage; 1999. p. 251-284.

Mataix-Cols D, Billotti D, Fernández de la Cruz L, Nordsletten AE. The London field trial for hoarding disorder. Psychological Medicine. 2013 Advance online publication. 10.1017/ S0033291712001560

Mataix-Cols D, Frost R, Pertusa A, Clark L, Saxena S, Leckman J, Wilhelm S. Hoarding disorder: A new diagnosis for DSM-5? Depression and Anxiety. 2010; 27:556-572. [PubMed: 20336805]

Mueller A, Mitchell JE, Crosby RD, Glaesmer H, de Zwaan M. The prevalence of compulsive hoarding and its association with compulsive buying in a German population-based sample. Behaviour Research and Therapy. 2009; 47:705-709. [PubMed: 19457476] 
Muthén, LK.; Muthén, BO. Mplus 5.0 (Computer software). Los Angeles: Author; 1998-2009.

Pertusa A, Frost RO, Fullana MA, Samuels J, Steketee G, Tolin D, Mataix-Cols D. Refining the diagnostic boundaries of compulsive hoarding: A critical review. Clinical Psychology Review. 2010; 30:371-386. [PubMed: 20189280]

Samuels JF, Bienvenu OJ, Grados MA, Cullen B, Riddle MA, Liang K, Nestadt G. Prevalence and correlates of hoarding behavior in a community-based sample. Behaviour Research and Therapy. 2008; 46:836-844. [PubMed: 18495084]

Samuels JF, Bienvenu OJ, Pinto A, Fyer AJ, McCracken JT, Rauch SL, Nestadt G. Hoarding in obsessive-compulsive disorder: Results from the OCD Collaborative Genetics Study. Behaviour Research and Therapy. 2007a; 43:673-686. [PubMed: 16824483]

Samuels J, Shugart YY, Grados MA, Willour VL, Bienvenu OJ, Greenberg BD, Nestadt G. Significant linkage to compulsive hoarding on chromosome 14 in families with obsessive compulsive disorder. American Journal of Psychiatry. 2007b; 164:493-499. [PubMed: 17329475]

Saxena S, Ayers CR, Maidment KM, Vapnik T, Wetherell JL, Bystritsky A. Quality of life and functional impairment in compulsive hoarding. Journal of Psychiatric Research. 2011; 45:475480. [PubMed: 20822778]

Steiger JH. Structural model evaluation and modification: An interval estimation approach. Multivariate Behavioral Research. 1990; 25:173-180.

Steketee G, Frost R. Compulsive hoarding: Current status of the research. Clinical Psychology Review. 2003; 23:905-927. [PubMed: 14624821]

Steketee G, Frost R, Tolin D, Rasmussen J, Brown T. Waitlist-controlled trial of cognitive behavior therapy for hoarding disorder. Depression and Anxiety. 2010; 27:476-484. [PubMed: 20336804]

Thordarson D, Radomsky A, Rachman S, Shafran R, Sawchuk C, Hakstian A. The Vancouver Obsessional Compulsive Inventory (VOCI). Behaviour Research and Therapy. 2004; 42:12891314. [PubMed: 15381439]

Timpano KR, Exner C, Glaesmer H, Rief W, Keshaviah A, Brahler E, Wilhelm S. The epidemiology of the proposed DSM-5 hoarding disorder: Exploration of the acquisition specifier, associated features, and distress. Journal of Clinical Psychiatry. 2011; 72:780-786. [PubMed: 21733479]

Tolin D, Frost R, Steketee G. A brief interview for assessing compulsive hoarding: The Hoarding Rating Scale-Interview. Psychiatry Research. 2010; 178:147-152. [PubMed: 20452042]

Tolin D, Frost R, Steketee G. An open trial of cognitive-behavioral therapy for compulsive hoarding. Behaviour Research and Therapy. 2007; 45:1461-1470. [PubMed: 17306221]

Tolin DF, Frost RO, Steketee G, Fitch KE. Family burden of compulsive hoarding: Results of an Internet survey. Behaviour Research and Therapy. 2008a; 46:334-344. [PubMed: 18275935]

Tolin DF, Frost RO, Steketee G, Gray KD, Fitch KE. The economic and social burden of compulsive hoarding. Psychiatry Research. 2008b; 160:200-211. [PubMed: 18597855]

Tolin DF, Kiehl KA, Worhunsky P, Book GA, Maltby N. An exploratory study of the neural mechanisms of decision making in compulsive hoarding. Psychological Medicine. 2009; 39:325336. [PubMed: 18485263]

Tolin DF, Meunier SA, Frost RO, Steketee G. Course of compulsive hoarding and its relationship to life events. Depression and Anxiety. 2010; 27:829-838. [PubMed: 20336803]

Tolin DF, Stevens MC, Villavicencio AL, Norberg MM, Calhoun VD, Frost RO, Pearlson GD. Neural mechanisms of decision making in hoarding disorder. Archives of General Psychiatry. 2012; 69:832-841. [PubMed: 22868937]

Torres AR, Fontenelle LF, Ferrão YA, Conceição do Rosário M, Torresan RC, Miguel EC, Shavitt RG. Clinical features of obsessive-compulsive disorder with hoarding symptoms: A multicenter study. Journal of Psychiatric Research. 2012; 46:724-732. [PubMed: 22464941]

Tucker LR, Lewis C. A reliability coefficient for maximum likelihood factor analysis. Psychometrika. 1973; 38:1-10.

Watson D, Wu K. Development and validation of the Schedule of Compulsions, Obsessions, and Pathological Impulses (SCOPI). Assessment. 2005; 12:50-65. [PubMed: 15695743] 
Highlights

Convergent and discriminant validity of three hoarding domains were examined in a MTMM matrix.

The three-factor model provided an adequate fit for the data.

O Convergent validities were high, but hoarding factors evidenced poor discriminant validity.

Each factor discriminated hoarding from OCD patients and community controls. 


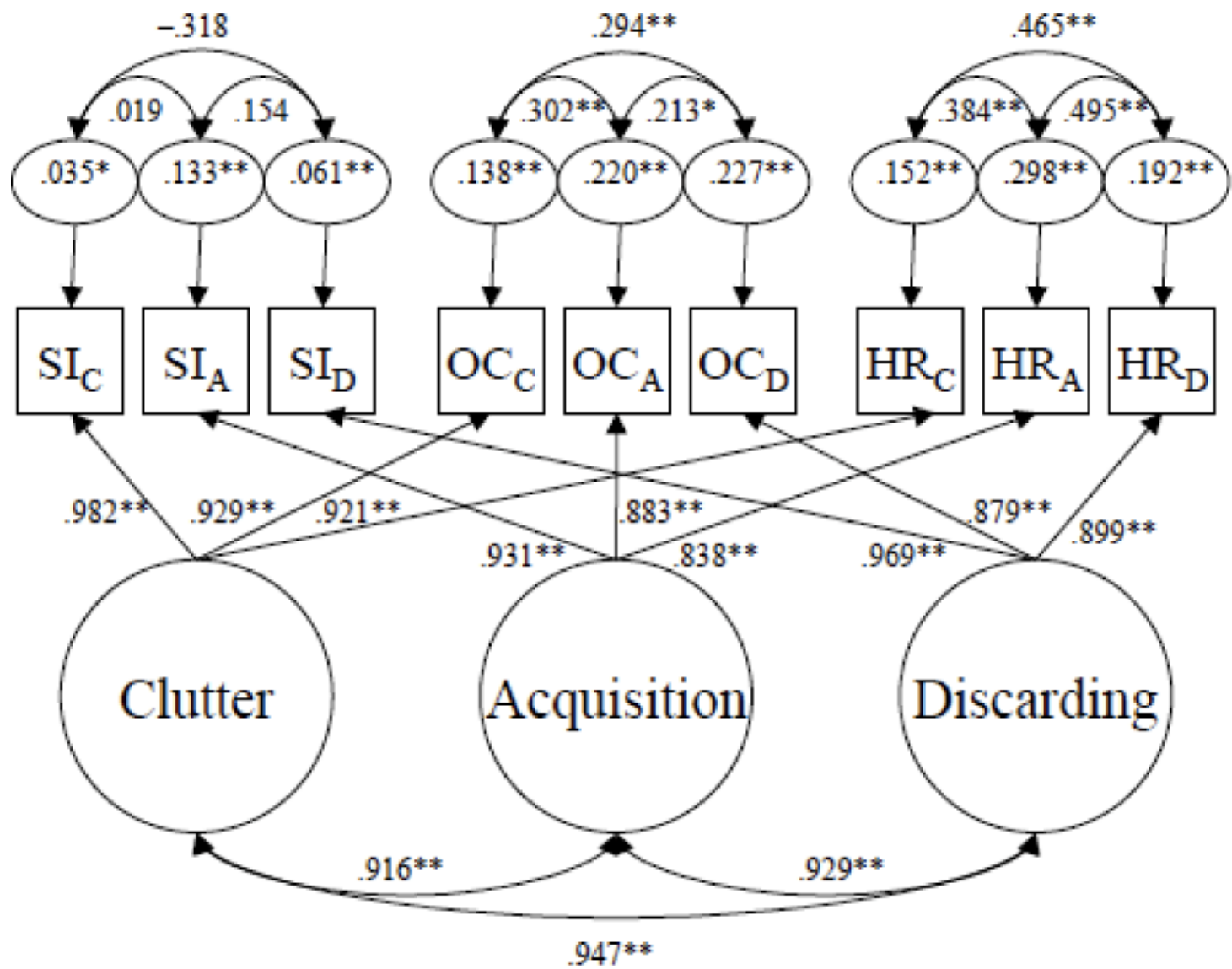

Figure 1.

Multitrait-multimethod correlated uniquenesses model of the key features of hoarding with completely standardized parameter estimates. $\mathrm{SI}_{\mathrm{C}}=$ clutter subscale items from the Saving Inventory-Revised, Modified Format (SI-R); $\mathrm{SI}_{\mathrm{A}}=$ acquisition subscale items from the SI$\mathrm{R} ; \mathrm{SI}_{\mathrm{D}}=$ difficulty discarding/saving subscale items from the SI-R; $\mathrm{OC}_{\mathrm{C}}=$ clutter item from the Obsessive-Compulsive Inventory-Revised (OCI-R); $\mathrm{OC}_{\mathrm{A}}=$ acquisition item from the OCI-R; $\mathrm{OC}_{\mathrm{D}}=$ discarding item from the OCI-R; $\mathrm{HR}_{\mathrm{C}}=$ clutter item from the Hoarding Rating Scale-Interview (HRS-I); $\mathrm{HR}_{\mathrm{A}}=$ acquisition item from the HRS-I; $\mathrm{HR}_{\mathrm{D}}=$ discarding item from the HRS-I. ${ }^{*} p<.01, * * p<.001$. 


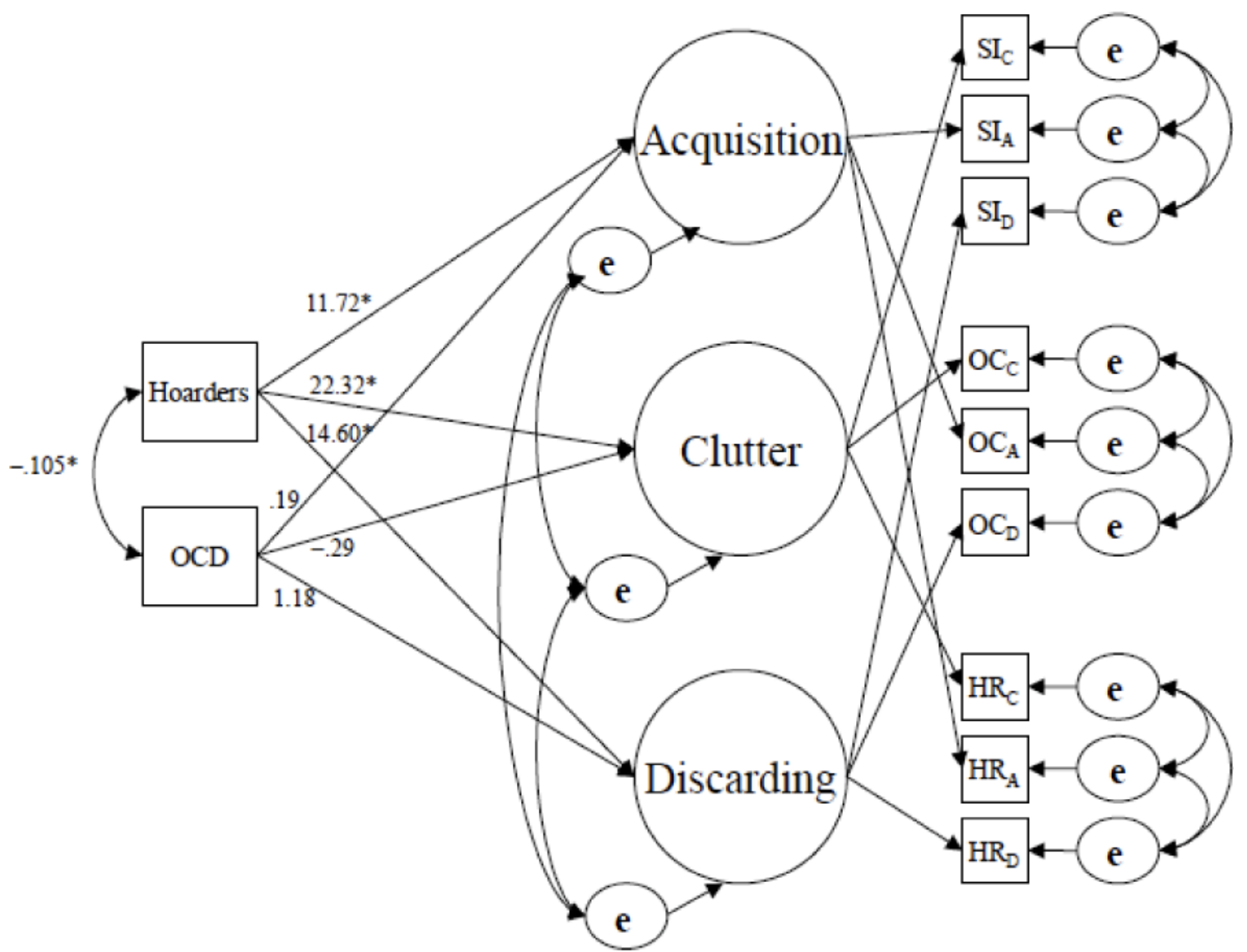

Figure 2.

Multitrait-multimethod correlated uniquenesses model with covariates and unstandardized parameter estimates. Hoarding and OCD are the dummy-coded covariates, and community controls are the reference group. $\mathrm{SI}_{\mathrm{C}}=$ clutter subscale items from the Saving InventoryRevised, Modified Format (SI-R); $\mathrm{SI}_{\mathrm{A}}=$ acquisition subscale items from the SI-R; $\mathrm{SI}_{\mathrm{D}}=$ difficulty discarding/saving subscale items from the SI-R; $\mathrm{OC}_{\mathrm{C}}=$ clutter item from the Obsessive-Compulsive Inventory-Revised (OCI-R); $\mathrm{OC}_{\mathrm{A}}=$ acquisition item from the OCI$\mathrm{R} ; \mathrm{OC}_{\mathrm{D}}=$ discarding item from the OCI-R; $\mathrm{HR}_{\mathrm{C}}=$ clutter item from the Hoarding Rating Scale-Interview (HRS-I); $\mathrm{HR}_{\mathrm{A}}=$ acquisition item from the HRS-I; $\mathrm{HR}_{\mathrm{D}}=$ discarding item from the HRS-I. ${ }^{*} p<.001$. 


\section{Table 1}

Descriptive Statistics

\begin{tabular}{|c|c|c|c|}
\hline & $\begin{array}{l}\text { Hoarding Group } \\
\qquad(N=178)\end{array}$ & $\begin{array}{l}\text { Obsessive-Compulsive Disorder Group } \\
\qquad(N=96)\end{array}$ & $\begin{array}{l}\text { Community Controls } \\
\qquad(N=130)\end{array}$ \\
\hline \multicolumn{4}{|l|}{ Age } \\
\hline - Range & $20-78$ & $18-74$ & $21-83$ \\
\hline - Mean $(S D)$ & $53.3^{\mathrm{a}}(9.46)$ & $34.5^{\mathrm{b}}(13.7)$ & $52.63^{\mathrm{a}}(13.48)$ \\
\hline$\%$ Female & $79.8 \%$ & $47.9 \%$ & $70 \%$ \\
\hline \multicolumn{4}{|l|}{ Ethnicity } \\
\hline - White & $86.0 \%$ & $85.6 \%$ & $88.3 \%$ \\
\hline - African American & $9.6 \%$ & $5.6 \%$ & $6.3 \%$ \\
\hline - Asian American & $1.7 \%$ & $5.6 \%$ & $3.1 \%$ \\
\hline - Native American & $.6 \%$ & $2.2 \%$ & $1.6 \%$ \\
\hline - Hispanic & $1.1 \%$ & $3.3 \%$ & $5.6 \%$ \\
\hline - Other & $1.1 \%$ & $1.1 \%$ & $.8 \%$ \\
\hline
\end{tabular}

Note. Means with different superscripts are significantly different from each other at $p<.001$. 


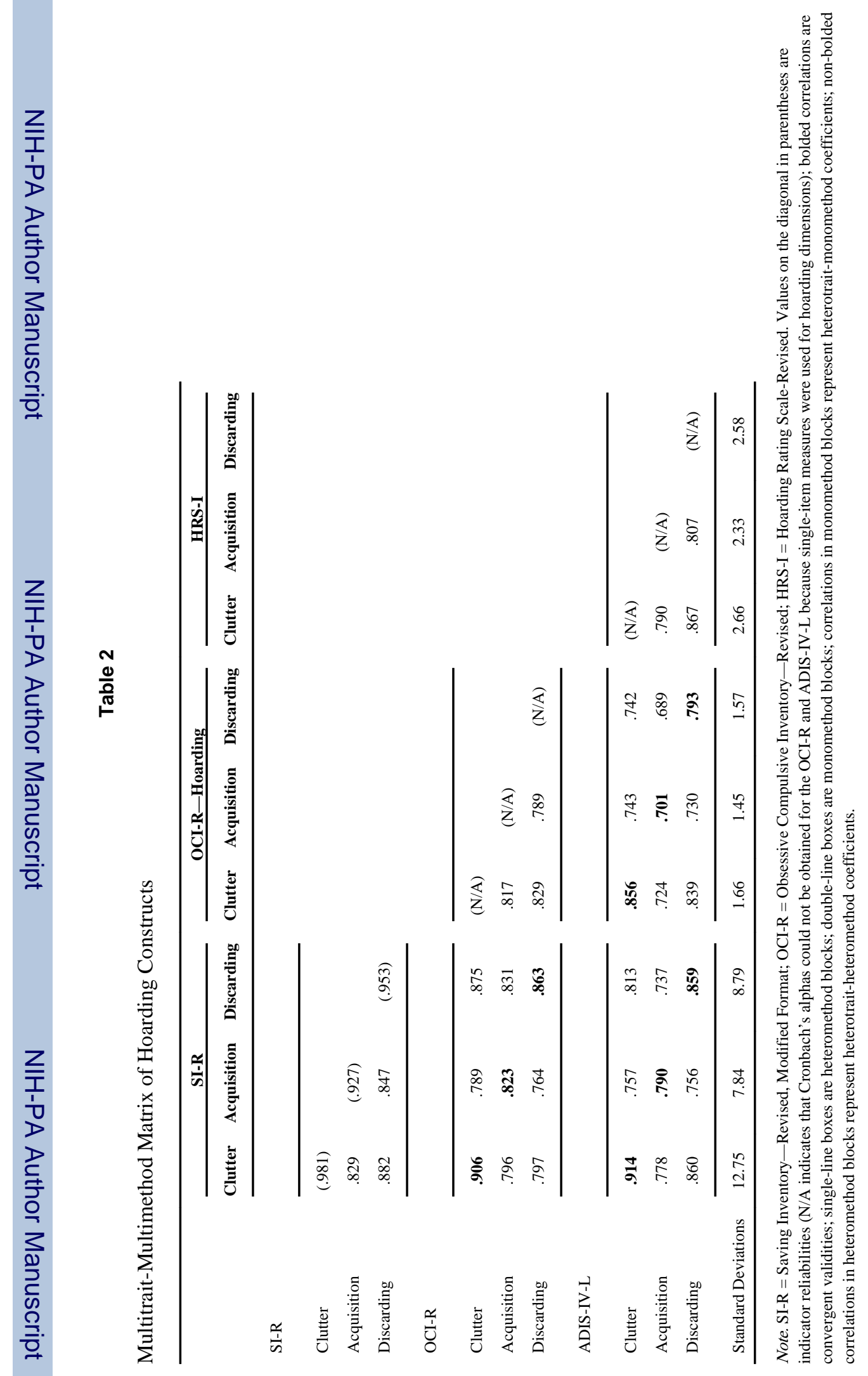

J Obsessive Compuls Relat Disord. Author manuscript; available in PMC 2014 July 01. 